Rev. Bras. Saúde Prod. Anim., Salvador, v.17, n.2, p.272-279 abr./jun., $2016 \quad$ http://www.rbspa.ufba.br ISSN 15199940

\title{
Desempenho e comportamento de suínos em fase de terminação submetidos a diferentes programas de luz ${ }^{1}$
}

\section{Performance and behavior of pigs in finish phase subject to different programs of lighting}

\author{
FERREIRA, Rony Antonio ${ }^{2 *}$; FASSANI, Édison José2 ${ }^{2}$ ROCHA, Leonardo Francisco da ${ }^{3}$; \\ OLIVEIRA, Rodrigo Fortunato de ${ }^{4}$; RIBEIRO, Bruna Pontara Vilas Boas ${ }^{4}$; ABREU, \\ Márvio Lobão Teixeira de ${ }^{2}$; CANTARELLI, Vinícius de Souza ${ }^{2}$
}

\author{
${ }^{1}$ Estudo financiado pela FAPEMIG. \\ ${ }^{2}$ Universidade Federal de Lavras, Departamento de Zootecnia, Lavras, Minas Gerais, Brasil. \\ ${ }^{3}$ Universidade Federal de Minas Gerais, Escola de Veterinária, Programa de Pós-Graduando em Zootecnia, \\ Belo Horizonte, Minas Gerais, Brasil. \\ ${ }^{4}$ Universidade Federal de Lavras, Programa de Pós-Graduando em Zootecnia, Lavras, Minas Gerais, Brasil. \\ *Endereço para correspondência: rony@dzo.ufla.br
}

\section{RESUMO}

Objetivou-se com esse trabalho avaliar o uso de programas de luz sobre o desempenho, concentração plasmática de melatonina e comportamento de suínos em fase de terminação. $\mathrm{O}$ experimento foi conduzido no setor de suinocultura da UFLA, utilizando-se 32 suínos em fase de terminação, por 48 dias. Os animais foram alojados em grupos de dois em cada baia (unidade experimental), distribuídos em delineamento em blocos casualizados, de acordo com o peso inicial com quatro tratamentos e quatro blocos. Foram utilizados quatro programas de luz (tratamentos), sendo T1: luz natural (LN); T2: 15 horas de luz e nove de escuro por dia (15L: 9E); T3: 19 horas de luz por dia (19L: 5E); T4: 23 horas de luz por dia (23L: 1E). As variáveis analisadas foram $\mathrm{o}$ desempenho (consumo de ração médio diário, ganho de peso médio diário e conversão alimentar), concentração plasmática de melatonina e o comportamento (bebendo, fuçando, ócio e comendo). A alteração no fotoperíodo não alterou o desempenho ou a concentração plasmática de melatonina nos suínos. As variáveis comportamentais "fuçando", "comendo", "bebendo", não diferiram em nenhum dos períodos estudados, porém o comportamento ócio foi mais ocorrente nos suínos que receberam 15 horas de luz. O aumento no fotoperíodo não permitiu expressivas alterações de desempenho ou de comportamento dos animais.

Palavras-chave: ambiente, comportamento animal, fotoperíodo, suinocultura

\section{SUMMARY}

The aim of this study was to evaluate the use of lighting programs on performance, plasma concentration of melatonin and behavior of finishing pigs. The experiment was conducted in the pig farming sector UFLA, using 32 pigs in the finishing phase, for 48 days. The animals were housed in groups of two in each pen (experimental unit), distributed in a randomized block design, according to the initial weight. Four light periods were used (treatments): T1: natural light (LN); T2: 15 hours of light and dark by day nine (15L: 9E); T3: 19 hours light per day (19L: 5E); T4: 23 hours of light per day (23L: 1D). The variables analyzed were the performance (average daily feed consumption, average daily gain weight and feed conversion), the plasma concentrations of melatonin and the behavior (drinking, sniffing, leisure and eating). The change in photoperiod did not affect performance or melatonin concentration in pigs. The behavioral variables "digging", "eating", "drinking", did not differ in any of the periods studied, but leisure behavior was more occurring to the pigs receiving 15 hours of light. The increase in photoperiod showed no significant changes in performance or behavior of the animals.

Keywords: animal behavior, environment, photoperiod, swine 
Rev. Bras. Saúde Prod. Anim., Salvador, v.17, n.2, p.272-279 abr./jun., 2016 http://www.rbspa.ufba.br

\section{INTRODUÇÃO}

O ambiente é fator importante dentre os meios de possibilitar a expressão do potencial genético produtivo dos suínos e os elementos e fatores climáticos contribuem para esta expressão, associados ao bem estar. O fotoperíodo é um fator ambiental cujos efeitos já foram elucidados para outras espécies como as aves, por exemplo. Entretanto, o uso de luz artificial poderia contribuir para o bem-estar do suíno e ser uma alternativa de manejo produtivo, que possibilitaria ao animal alterar seu comportamento ingestivo em função da disponibilidade luminosa e dos horários de temperaturas mais amenas.

A luminosidade está relacionada com as necessidades básicas como alimentação, água e temperatura. Os ritmos diários de atividade dos animais são fortemente influenciados e determinados pelas condições de luz ao longo do dia. Embora o ritmo circadiano endógeno tenha influência direta da luz, a literatura disponível sobre tal assunto, em suínos, é relativamente escassa.

Em avicultura de corte, por exemplo, já são evidentes os efeitos benéficos dos programas de luz como fator positivo, principalmente durante o período de calor, proporcionando maior consumo de alimentos durante a noite, quando ocorrem temperaturas mais amenas (LIBONI et al., 2013). Em suinocultura, por outro lado, os resultados sobre a influência da luz em relação ao comportamento, desempenho e bemestar são poucos e contraditórios.

Os estudos conduzidos por Van Putten (1980) não evidenciaram que o repertório comportamental dos suínos é afetado pela presença ou ausência de luz. No Brasil, o estudo de programas de luz para suínos se faz importante em razão da escassez de informação a respeito do tema (FURLAN et al., 1986a, 1986b; SOUSA JUNIOR et al., 2011). Além disso, é importante a atualização de estudos relacionados à respostas comportamentais e fisiológicas dos animais de genética moderna, que podem responder de maneira diferente aos programas de luz.

Os mamíferos respondem ao fotoperíodo por alteração na produção de melatonina, um mensageiro endócrino que afeta $o$ comportamento dos animais (HISSA et al., 2008). Em suínos, podem ocorrer padrões diferenciados de produção noturna de melatonina em função da idade dos animais, podendo apresentar sensibilidade variável à flutuação do fotoperíodo (ANDERSON, 2001), o que poderia alterar o comportamento e o desempenho dos mesmos.

Com este trabalho teve-se o objetivo de avaliar a influência de diferentes programas de luz sobre o desempenho, comportamento e concentração plasmática de melatonina de suínos em fase de terminação.

\section{MATERIAL E MÉTODOS}

O experimento foi conduzido no setor de suinocultura da UFLA, localizado no município de Lavras, MG, situado a $21^{\circ} 14^{\prime}$ de latitude sul e $45^{\circ}$ de longitude oeste, com altitude de $918 \mathrm{~m}$. O clima é Cwa, segundo a classificação de Köeppen, sendo caracterizado como clima temperado úmido, com inverno seco e verão úmido (DANTAS et. al, 2007).

O experimento foi conduzido utilizandose 32 suínos híbridos comerciais da genética DanBred, com peso médio inicial de $63,83 \pm 5,06 \mathrm{~kg}$ e idade de $102,0 \pm 3,02$ dias. O uso dos animais foi aprovado pela CEUA (Comissão de ética no uso de animais) protocolo $014 / 10$. Os 
Rev. Bras. Saúde Prod. Anim., Salvador, v.17, n.2, p.272-279 abr./jun., 2016 http://www.rbspa.ufba.br ISSN 15199940

suínos foram alojados em galpão orientado na direção leste-oeste, construído em alvenaria, com telhado em duas águas com telhas de barro, pé direito de $2,5 \mathrm{~m}$, possuindo baias com $3 \mathrm{~m}^{2}$ de área útil e muretas laterais de $0,9 \mathrm{~m}$ de altura. As baias possuíam piso de concreto compacto, equipadas com bebedouros do tipo chupeta e comedouro semi-automático.

As condições ambientais do galpão foram monitoradas diariamente sendo observadas temperatura de bulbo seco e de globo negro, umidade relativa, utilizando-se estação meteorológica portátil modelo Oregon Scientic WMR928NX, e termômetro de globo negro, marca Instrutherm. Os dados foram obtidos e armazenados a cada cinco minutos sendo utilizados para cálculo do ITGU (índice de temperatura de globo e umidade).

Os animais foram distribuídos em delineamento em blocos casualizados, de acordo com o peso inicial, em quatro tratamentos (programas de luz) sendo a unidade experimental composta por dois suínos (um macho e uma fêmea) na baia, com quatro blocos por tratamento. $\mathrm{O}$ critério para formação dos blocos foi o peso inicial dos animais. Os tratamentos, em período nictemeral (24 horas), foram: $\mathrm{LN}$, luz natural (12h de luz); programa de luz, com suplementação de luz artificial totalizando 15 horas de luz e 9 horas de escuro (15L:9E); programa de luz com 19L:5E e programa de luz com 23L:1E. A iluminação artificial suplementar na definição dos tratamentos foi provida por meio de lâmpadas fluorescentes compactas de 25 W cada, sendo utilizada uma lâmpada para três baias, sobre a parede divisória das mesmas, a uma altura de $2 \mathrm{~m}$ do piso, responsáveis pelo fornecimento médio de 290 lux ao nível dos olhos dos suínos. Como o experimento foi realizado em galpão único, este foi dividido em quatro segmentos, sendo utilizadas quatro baias em cada, isolados por parede de alvenaria no sentido transversal e utilizada lona plástica preta para fechamento das laterais, sendo esta fechada à noite somente no respectivo período de escotofase de cada tratamento, de modo a evitar a influência entre os programa de luz e fases da lua.

O experimento teve duração de 48 dias e em três dias, escolhidos aleatoriamente, no início meio e terço final do período, foram verificadas as características de comportamento dos suínos por meio de etograma comportamental. As ocorrências comportamentais foram observadas em imagens captadas a intervalo de um minuto durante $o$ período de 24 horas ininterruptas, capturadas por câmaras digitais instaladas no galpão experimental. Para captura das imagens foram utilizadas câmaras JFL CFTV com infravermelho, marca sony, sendo instaladas duas por tratamento, totalizando oito câmaras.

As imagens foram armazenadas em gravador modelo Stand Alone DVR para leituras posteriores. Para se obter a frequência percentual do repertório comportamental dos animais, os resultados de observação das imagens foram digitalizados em planilha eletrônica elaborada com as atividades pré-determinadas baseado nos atos de comer, beber, fuçar e ócio, semelhante ao etograma utilizado por Castro et al. (2011). Foram realizadas 1.440 leituras por animal experimental em cada dia analisado, totalizando 4.320 leituras por animal.

Os suínos foram alimentados com rações formuladas à base de milho, farelo de soja e farelo de trigo, de modo a atender as exigências dos animais conforme recomendações das Tabelas Brasileiras (ROSTAGNO et al., 2011) para suínos de alto potencial genético de desempenho médio nas respectivas 
fases de terminação (70 a 100kg) e pósterminação $(100 \mathrm{a} 120 \mathrm{~kg})$. As rações e a água foram fornecidas à vontade. Foi mensurada a quantidade total fornecida e consideradas as sobras e o desperdício de ração para cálculo do consumo de ração médio diário (CRMD). Os animais foram pesados no início e ao final do período experimental, para cálculo do ganho de peso médio diário (GPMD). A conversão alimentar (CA) foi calculada com base no consumo de ração total no período, dividido pelo ganho de peso total no período.

Ao final do período experimental foi coletado sangue de todos os animais para dosar a concentração de melatonina. A coleta foi feita por punção da veia jugular, no período noturno para obtenção do soro sanguíneo analisado utilizando-se kit imunoenzimático (ELISA) da marca Cloud-Clone Corp.

Para análise comportamental, foi utilizada estatística não paramétrica, descrevendo os comportamentos em frequência de ocorrência (\%), sendo os dados analisados pelo teste de Friedman ao nível de 5\%, utilizando-se o pacote computacional ACTION 2.0. Para as variáveis de desempenho foram avaliados o CRMD, o GPMD e a CA sendo os resultados submetidos à análise de variância e teste $\mathrm{F}$ utilizando o pacote computacional SISVAR (FERREIRA, 2008).

\section{RESULTADOS E DISCUSSÃO}

Durante o período experimental, no interior do galpão, a temperatura média manteve-se em $19,6 \pm 3,4^{\circ} \mathrm{C}$, com mínimas de $13 \pm 2,1^{\circ} \mathrm{C}$ e máximas de
$29,3 \pm 3,8^{\circ} \mathrm{C}$. A temperatura média do globo negro foi de $20,6 \pm 3,54^{\circ} \mathrm{C}$, sendo ITGU calculado de 66,3 $\pm 5,6$. Neste ambiente, os animais estavam em início de tensão por calor, pois a temperatura média durante o período experimental esteve acima dos valores recomendados que para esta fase esteja compreendida entre 15 e $18^{\circ} \mathrm{C}$ (Ferreira, 2011). A temperatura máxima extrapolou a temperatura critica superior para a categoria, que de acordo com os mesmos autores é de $27^{\circ} \mathrm{C}$. É oportuno ressaltar que a amplitude térmica foi superior àquela tolerada pelos suínos desta categoria, que é em torno de $8^{\circ} \mathrm{C}$ (FERREIRA, 2011). A umidade relativa observada foi de $66,2 \pm 11,85 \%$, estando a média situada entre os limites considerados confortáveis, preconizadas por Leal \& Nããs (1992).

Os resultados de desempenho dos suínos estão apresentados na Tabela 1 . Não foi constatado efeito $(\mathrm{P}>0,05)$ do uso de programas de luz sobre as variáveis de desempenho estudadas. Neste estudo, o fornecimento de luz suplementar não foi eficiente em estimular o consumo noturno, quando os animais estiveram em situação de temperaturas mais amenas, o que poderia ser importante para os suínos nos momentos de tensão por calor. A massa corporal dos animais pode ter influenciado nestes resultados. Animais de maior massa corporal, como foi o caso daqueles utilizados no presente trabalho, apresentam a possibilidade de permitir a conservação do calor corporal, possibilitando termólise durante a noite em temperaturas mais amenas. Esta resposta comportamental poderia permitir menor efeito sobre o consumo de ração ao longo do dia (MARTINEZ-RAMIREZ et al., 2008). 
Rev. Bras. Saúde Prod. Anim., Salvador, v.17, n.2, p.272-279 abr./jun., 2016 http://www.rbspa.ufba.br ISSN 15199940

Tabela 1. Resultados de consumo de ração médio diário (CRMD), ganho de peso médio diário (GPMD), conversão alimentar (CA), peso final (PF) e de melatonina obtidos com suínos em terminação submetidos a diferentes programas de luz

\begin{tabular}{|c|c|c|c|c|c|c|}
\hline \multirow{2}{*}{ Variáveis } & \multicolumn{4}{|c|}{ Tratamentos } & \multirow{2}{*}{ CV (\%) } & \multirow{2}{*}{$\mathrm{P}<$} \\
\hline & $\overline{\mathrm{LN}}$ & 15L:9E & 19L:5E & 23L:1E & & \\
\hline CRMD (kg) & 3,30 & 3,28 & 3,20 & 3,16 & 7,56 & 0,629 \\
\hline GPMD (kg) & 1,09 & 1,09 & 1,04 & 1,10 & 7,99 & 0,588 \\
\hline $\mathrm{CA}$ & 3,05 & 3,03 & 3,07 & 2,89 & 9,39 & 0,572 \\
\hline PF (kg) & 117,33 & 115,58 & 112.67 & 117,92 & 4,25 & 0,167 \\
\hline Melatonina $(\mathrm{pg} / \mathrm{mL})$ & 11,27 & 10,63 & 10,85 & 10,92 & 9,22 & 0,6487 \\
\hline
\end{tabular}

Valores estatisticamente iguais pelo Teste $\mathrm{F}$, considerando diferença significativa $\mathrm{P}<0,05$.

Estes resultados estão de acordo com os obtidos por Furlan et.al. (1986a), que trabalhando com suínos em terminação não encontraram diferenças sobre $\mathrm{o}$ ganho de peso e consumo de ração dos animais expostos a programas hemerais com 18 e 24 horas de luz. Semelhantemente, Amaral et al. (2014), trabalhando com suínos em terminação recebendo diferentes programas de luz, não observaram efeito do fotoperíodo sobre o desempenho dos animais.

$\mathrm{O}$ fornecimento de luz artificial não alterou $(\mathrm{P}>0,05)$ a produção de melatonina nos suínos. Normalmente, a presença de luz afeta a retina estimulando o nervo óptico, o quiasma óptico e o núcleo hipotalâmico supraquiasmático, aumentando a atividade do nervo simpático da glândula pineal, levando à inibição das enzimas $\mathrm{N}$-acetil-serotonina e hidroxi-indol-O-metiltransferase. Esta reação à luz promove altos níveis plasmáticos de serotonina e baixos níveis plasmáticos de melatonina (5-metoxi-Nacetiltriptamina). Entretanto, estas enzimas são ativadas em determinadas intensidades luminosas (HISSA et al., 2008). Conforme apresentado por Zonderland et al. (2009), alguns estudos citam que há necessidade de 40 lux para tal estimulação, o que foi atendido neste experimento, onde os animais receberam iluminação artificial de 290 lux, ao nível dos olhos, mas que, ainda assim, não promoveram alteração nos padrões de secreção de melatonina, com alteração no tempo de exposição à luz.

Tabela 2. Ocorrência (\%) dos comportamentos observados com suínos em terminação submetidos a diferentes programas de luz

\begin{tabular}{lcccc}
\hline \multirow{2}{*}{ Comportamento } & \multicolumn{4}{c}{ Programa de luz } \\
\cline { 2 - 5 } & LN & 15L:9E & 19L:5E & 23L:1E \\
\hline Fuçando & 10,1 & 7,9 & 12,9 & 11,8 \\
Comendo & 8,8 & 7,3 & 10,8 & 09,6 \\
Bebendo & 0,7 & 0,5 & 0,4 & 01,1 \\
Ócio* & $80,4^{\mathrm{b}}$ & $84,3^{\mathrm{c}}$ & $75,7^{\mathrm{a}}$ & $77,4^{\mathrm{b}}$ \\
\hline Total (\%) & 100 & 100 & 100 & 100 \\
\hline
\end{tabular}

*Médias seguidas de letras diferentes, nas linhas, diferem estatisticamente entre si pelo teste de Friedman, ao nível de 5\% de probabilidade. 
Rev. Bras. Saúde Prod. Anim., Salvador, v.17, n.2, p.272-279 abr./jun., 2016 http://www.rbspa.ufba.br ISSN 15199940

Pode-se observar que, de maneira geral, todos os animais passaram a maior parte do seu tempo em ócio (Tabela 2). Como apresentado por Broom \& Fraser (2010), o ócio, caracterizado pela soma dos comportamentos de descanso e sono, é importante, pois, um indivíduo imóvel em uma posição não visível tem menores chances de ser detectado pelo predador, além de ter a função de conservação de energia. Este período de ócio é importante, também, para reparação dos níveis normais das atividades neuronais (GUYTON \& HALL, 1997). Os suínos, dentre os animais de produção, são os que gastam maior tempo descansando; estes apresentam o sono de ondas lentas (SWSslow-wave sleep) e o sono paradoxal, com rápido movimento dos olhos (REMrapid eye movements), sendo que, em média o SWS ocupa seis horas diárias e o REM 1,75h em vários períodos do dia (BROOM \& FRASER, 2010).

Ao se analisar o fornecimento de luz artificial ao longo do período nictemeral, observa-se que o fornecimento de 15 horas de luz $(15 \mathrm{~L}: 9 \mathrm{E})$ aumentou $(\mathrm{P}<0,01)$ a ocorrência de ócio em comparação com os demais períodos de luminosidade. Apesar de ser predominante entre os demais comportamentos, a ocorrência de ócio foi menor nos demais tratamentos, seguindo uma sequência sem explicação biológica definida.

Os resultados obtidos são condizentes com os que foram encontrados por Broom \& Fraser (2010), que afirmaram que, dentre todos os animais de produção, os suínos são os que passam maior parte do tempo descansando e dormindo, podendo chegar a 19 horas/dia, quando confinados.

Em outro estudo com leitões mantidos sob ambiente de conforto térmico $\left(21^{\circ} \mathrm{C}\right)$, os animais permaneceram $82 \%$ do tempo deitados (KIEFER et al., 2010). Adicionalmente, Taylor et al. (2006), estudando o fornecimento de diferentes quantidade de luz para suínos em crescimento, observaram que os animais preferiam áreas menos iluminadas para descansar e, mais iluminadas para defecar.

Pode-se constatar que o comportamento em ócio seja naturalmente predominante na espécie, pois eles o realizam com maior frequência mesmo que com fotoperíodos distintos, o que seria, talvez, um comportamento que oferece conforto e prazer para o animal. Hötzel et al. (2010) mencionaram uma definição de comportamento natural proposta por outros autores: "comportamento natural é aquele que o animal tende a realizar sob condições naturais, porque é prazeroso e promove bom funcionamento biológico". Por outro lado, os suínos que são alojados em ambientes áridos, monótonos, com falta de substratos, podem refletir frustração em comportamentos anômalos. Conclui-se que suínos de alto potencial genético para produção de carne em fase de terminação não responderam à suplementação artificial de luz. Portanto, não se recomenda o uso de programa de luz para esta categoria de animais.

\section{REFERÊNCIAS}

\section{ANDERSON, H. Plasma melatonin levels in relation to the light-dark cycle and parental background in domestic pigs. Acta Veterinária Scandinavica, v.42, p.287-294, 2001.}

AMARAL, P.I.S.; FERREIRA, R.A.; PIRES, A.V.; FONSECA, L.S.; GONÇALVES, S.A.; SOUZA, G.H.C. Desempenho, comportamento e respostas físiológicas de suínos em terminação submetidos a diferentes programas de luz. Journal Animal Behaviour Biometeorology, v.2, n.2, p.54-59, 2014. 
Rev. Bras. Saúde Prod. Anim., Salvador, v.17, n.2, p.272-279 abr./jun., 2016 http://www.rbspa.ufba.br ISSN 15199940

BROOM, D.M.; FRASER, A.F. Comportamento e bem-estar de animais domésticos. 4.ed. São Paulo: Manole, 2010. 452p.

CASTRO, J.O.; CAMPOS, A.T.; FERREIRA, R.A.; YANAGI JÚNIOR, T.; TADEU, H.C. Uso de ardósia na construção de celas de maternidade: I Efeito sobre o ambiente e comportamento de suínos. Engenharia Agrícola, v.31, p.458, 2011.

DANTAS, A.A.A.; CARVALHO, L.G.; FERREIRA, E. Classificação e tendências climáticas em Lavras, MG. Ciência e Agrotecnologia, v.31, n. 6, 2007.

FERREIRA, D.F. SISVAR: um programa para análises e ensino de estatística. Revista Symposium, v. 6, p.36-41, 2008.

FERREIRA, R.A. Maior produção com melhor ambiente para aves, suínos e bovinos. 2.ed. Viçosa, MG. Aprenda Fácil, 2011. 374p.

FURLAN, A.C.; LIMA, J.A.F.; OLIVEIRA, A.I.G.; SOARES, M.C.; OLIVEIRA, B.L. Diferentes períodos de luz para suínos em crescimento e terminação: experimento I. Revista Brasileira de Zootecnia, v.15, n.5, p.372-377, 1986a.

FURLAN, A.C.; LIMA, J.A.F.; OLIVEIRA, A.I.G.; SOARES, M.C.; OLIVEIRA, B.L. Diferentes períodos de luz para suínos em crescimento e terminação: experimento II. Revista Brasileira de Zootecnia, v.15, n.5, p.378-383, 1986b.

GUYTON, A.C.; HALL, J.E. Tratado de fisiologia médica. Rio de Janeiro: Guanabara Koogan, 1997. 830p.
HISSA, N.M.; LIMA, G.G.; SIMÕES, J.C.; NUNES, R.T.L. Melatonina e a glândula pineal. Revista Eletrônica Pesquisa Médica, v.2, n.4, 2008.

HÖTZEL, M.J.; NOGUEIRA, S.S.C.; MACHADO FILHO, L.C.P. Bem-estar de animais de produção: das necessidades animais às possibilidades humanas. Revista de Etologia, v.9, n.2, p.1-10, 2010.

KIEFER, C.; MOURA, M.S.; SILVA, E.A.; SANTOS, A.P.; SILVA, C.M.; LUZ, M.F.; NANTES, C.L. Respostas de suínos em terminação mantidos em diferentes ambientes térmicos. Revista Brasileira de Saúde e Produção Animal [online], v.11, n.2, p.496-504, 2010.

LEAL, P.M.; NÃ̃̃S I.A. Ambiência animal. In: CORTEZ, L.A.B.; MAGALHÃES, P.S.G.(Org.). Introdução à engenharia agrícola. Campinas, SP: Unicamp, 1992. p.121135.

LIBONI, B. S.; YOSHIDA, S. H.; PACHECO, A. M.; MONTANHA, F. P.; SOUZA, L. F. A.; ASTOLPHI, J. L.; ASTOLPHI, M. Z. Diferentes programas de luz na criação de frangos de corte.

Revista Científica Eletrônica de Medicina Veterinária, v.11, n.20, 2013.

MARTINEZ-RAMIREZ, H.R.; JEAUROND, E.A.; LANGE, C.F.M. Dynamics of body protein deposition and changes in body composition after sudden changes in amino acid intake: II. Entire male pigs. Journal of Animal Science, v.86, n.3, p.2168-2179, 2008.

ROSTAGNO, H.S.; ALBINO, L.F.T.; DONZELE, J.L.; GOMES, P.C.; FERREIRA, A.S.; OLIVEIRA, R.F.; LOPES, D.C. Tabelas Brasileiras para Aves e Suínos. 3.ed. Viçosa: UFV, 2011. $252 p$. 
Rev. Bras. Saúde Prod. Anim., Salvador, v.17, n.2, p.272-279 abr./jun., 2016 http://www.rbspa.ufba.br

SOUSA JÚNIOR, V.R., ABREU, P.G., COLDEBELLA, A.; LOPES, L. S.;

LIMA, G. J. M. M.; SABINO, L. A.

Luz artificial no desempenho de leitões na fase de creche. Acta Scientiarum.

Animal Sciences, v.33, n.4, p.403-408, 2011.

TAYLOR, N.; PRESCOTT, N.; PERRY, G.; POTTER, M.; LE SUEUR, C.; WATHES, C.. Preference of growing pigs for illuminances. Applied Animal Behaviour Science, v.96, n.12, p.19-31, 2006.

VAN PUTTEN, G. Objective observations on the behaviour of fattening pigs. Animal Regulatory Studies, v.3, p.105-108, 1980.

ZONDERLAND, J.J.; CORNELISSEN, L.; WOLTHUIS-FILLERUP, M.;

SPOOLDER, H.A.M. Visual acuity of pigs at different light intensities. Applied Animal Behaviour Science, v.111, n.1-2, p.28-37, 2009.

Data de recebimento: 27/10/2015

Data de aprovação: 02/04/2016 